\title{
Revisiting the Airglow Image Analysis to Obtain and Visual Representation of the Spatial and Temporal Information
}

\author{
M. Sivakandan and *A. Taori \\ National Atmospheric Research Laboratory, Gadanki - 517112, India \\ *Email:alok.taori@gmail.com
}

\begin{abstract}
Airglow Imaging methods has been widely utilized to derive various parameters of the moving structures in the mesosphere-thermosphere-ionosphere system. Of late, imaging using the fisheye lens has become an important tool for mapping the whole sky. Such wide angle lens introduces significant distortions at more than $90^{\circ}$ look angles. Further, showcasing these images to elaborate the variability within a given night pose difficulties in terms of space and efforts required. We present a simple method to overcome this problem together with a comparison of the method proposed with existing method.
\end{abstract}

Key words: airglow, imaging, ionosphere, thermosphere, mesosphere, ESF, plasma, bubbles

\section{Introduction}

The solar energy impending on the earth's atmosphere interacts with different gases at different wavelengths. This interaction primarily depends on the size of the atom/molecule, absorption cross section, solar energy at the interacting wavelength and the angle of interaction. This interaction occurs at all the altitude regions and various atoms/molecules get energized in terms of getting dissociated, ionized, thermalized, or excited to their higher energy levels. In the collision dominated lower atmosphere, energy transfer from one atom to the other is so frequent that only highly energetic processes (such as lightening) are visible as glowing air. However, at upper atmospheric altitudes, life time of such excited states is large enough that upon their de-excitation to lower energy levels the radiation emitted by these species are detectable. These energy transfer processes are often referred as Chemiluminiscence and such detectable radiations are known as airglow emissions (e.g., Khomich et al., 2008). The airglow emissions are named as dayglow (occurring during daytime), nightglow (during nighttime) or twilightglow emissions. The prominent airglow emissions measured using ground based instruments are $\mathrm{OH}, \mathrm{Na}, \mathrm{O}_{2}, \mathrm{O}\left({ }^{1} \mathrm{~S}\right)$ and $\mathrm{O}\left({ }^{1} \mathrm{D}\right)$ whose peak emission altitudes are typically $85 \mathrm{~km}, 92 \mathrm{~km}, 94 \mathrm{~km}, 97 \mathrm{~km}$ and $250 \mathrm{~km}$, respectively. Further, as they are the outcome of Chemi-luminescence where more than single entity (atom/molecule) are involved in the energy exchange process, they are representative of the ambient around their peak emission altitudes. This also means that the variations in the background density and temperature get imprinted in the luminescence/intensity of the airglow emissions and thus they can be used to study the dynamical processes occurring at their peak emission altitudes (e.g., Taylor et al., 1998; Khomich et al., 2008). 
Since the last few decades, based on the above facts, airglow emissions have been widely used to study the upper atmospheric processes. The ground based measurements of airglow emissions can be of a narrow field of view photometric (e.g., Sridharan et al., 1998; Taori et al., 2011), spectrometric (e.g., Chakrabarty et al., 2002) or wide angle (large field of view) imaging (e.g., Mukherjee et al., 2003; Taylor et al., 2005) nature. Note that the daytime airglow monitoring is much more difficult than the nighttime, owing to the strong solar background and hence there are limited investigations. However, using a combination of Fabry-Perot etalon and narrow band interference filters the daytime airglow emissions monitoring has been made possible (e.g., Sridharan et al., 1998). Further, such daytime airglow monitoring has been successfully utilized to understand the variation of daytime mesospheric temperature variability (e.g., Sridharan et al., 1999) as well as the F-region processes (e.g., Taori et al., 2001). Another investigation revealed that daytime $\mathrm{O}\left({ }^{1} \mathrm{~S}\right)$ emission, which generally is treated to represent mesosphere, has a significant contribution from the F - region (Taori et al., 2003). On contrary to the limited airglow investigations during daytime, there are plenty of investigations that use the night time airglow measurements and study the mesospheric and thermospheric processes (e.g., Takahashi et al., 1985; Nakamura et al., 1999; Batista et al., 2000; Mukherjee et al., 2003; Taylor et al., 2005; Taori et al. 2005, 2012). In particular, the investigations using the mesospheric $\mathrm{OH}$ and $\mathrm{O}\left({ }^{1} \mathrm{~S}\right)$ emissions imaging deal with the gravity wave propagation characteristics, including their dissipation processes (e.g., Taylor et al., 1997; Batista et al., 2002; Ejiri et al., 2010; Narayanan et al., 2012; Sivakandan et al., 2015). The image measurements using $O\left({ }^{1} \mathrm{D}\right)$ emissions have been widely used to study the plasma processes such as equatorial plasma bubbles or plasma depletions (e.g., Makela and Otsuka, 2012) occurring at about $200-300$ km altitudes (e.g., Mendillo et al., 1997; Mukherjee et al., 2003; Chapagain et al., 2012; Makela et al., 2004; Ghodpage et al., 2014; Taori and Sindhya, 2014).

In a nut-shell, the image measurements provide good temporal and spatial information of the processes occurring in the mesosphere lower thermosphere ionosphere system. To derive the velocity and the spatial scales of the identified perturbations (i.e., gravity wave features in the mesosphere and plasma depletions in the thermosphere), most of the investigators use intensity measurements at a particular location (or pixels) and cross correlate the structures (e.g., Pimmenta et al., 2003; Sharma et al., 2014). There have been very few efforts to explain the 2-dimensional information with the temporal evolution characteristics (e.g., Taori et al., 2010; Narayanan et al., 2012). The present study elaborates this method in detail for the extraction of information from airglow imaging methods.

\section{Instrumentation}

To demonstrate the spatio-temporal mapping capability of the image measurements, we have used the data collected with the help of NARL Airglow Imager (NAI), located at Gadanki (shown in Fig. 1). NAI is equipped with $24 \mathrm{~mm}$ of Mamiya fish eye lens for all sky viewing. It monitors $\mathrm{OH}$ (peak wavelength $840 \mathrm{~nm}$ ), $\mathrm{O}\left({ }^{1} \mathrm{~S}\right)$ (peak wavelength $558 \mathrm{~nm}$ ), and $\mathrm{O}\left({ }^{1} \mathrm{D}\right)$ (peak wavelength $630 \mathrm{~nm}$ ) emissions and has a 1024x1024 pixels CCD as the detector which provides the horizontal structures of existing perturbations in the mesosphere thermosphere ionosphere system. To enhance the image quality, we average 2 pixels on the chip with resulting image size 512x512 pixels. The imager is optimized for best viewing at 
Open access e-Journal

Earth Science India, eISSN: $0974-8350$

Vol. 8 (III), July, 2015, pp. 50 - 60

http://www.earthscienceindia.info/

these 3 wavelengths, hence the best images of mesospheric waves are noted in the $\mathrm{O}\left({ }^{1} \mathrm{~S}\right)$ emissions, which originate at $\sim 92-102 \mathrm{~km}$ (with a peak emission altitude of $\sim 97 \mathrm{~km}$ ). At the same time, near simultaneous mapping the F-region plasma structures are performed with the help of $O\left({ }^{1} \mathrm{D}\right)$ emission monitoring. The exposure time used to measure the $O\left({ }^{1} \mathrm{~S}\right)$ and $O\left({ }^{1} \mathrm{D}\right)$ emissions intensities was $110 \mathrm{~s}$ while it is $16 \mathrm{~s}$ for the $\mathrm{OH}$ emission. To derive the 2dimensional parameters of perturbations (i.e., waves in mesosphere and plasma depletions in ionosphere), after capturing, the images have been analyzed and corrected for the background brightness and actual coordinates. Further, we also correct the images for Barrel distortion which arise due to the lens curvature effect as explained in following sections. More details of the NAI are discussed by Taori et al. (2013).

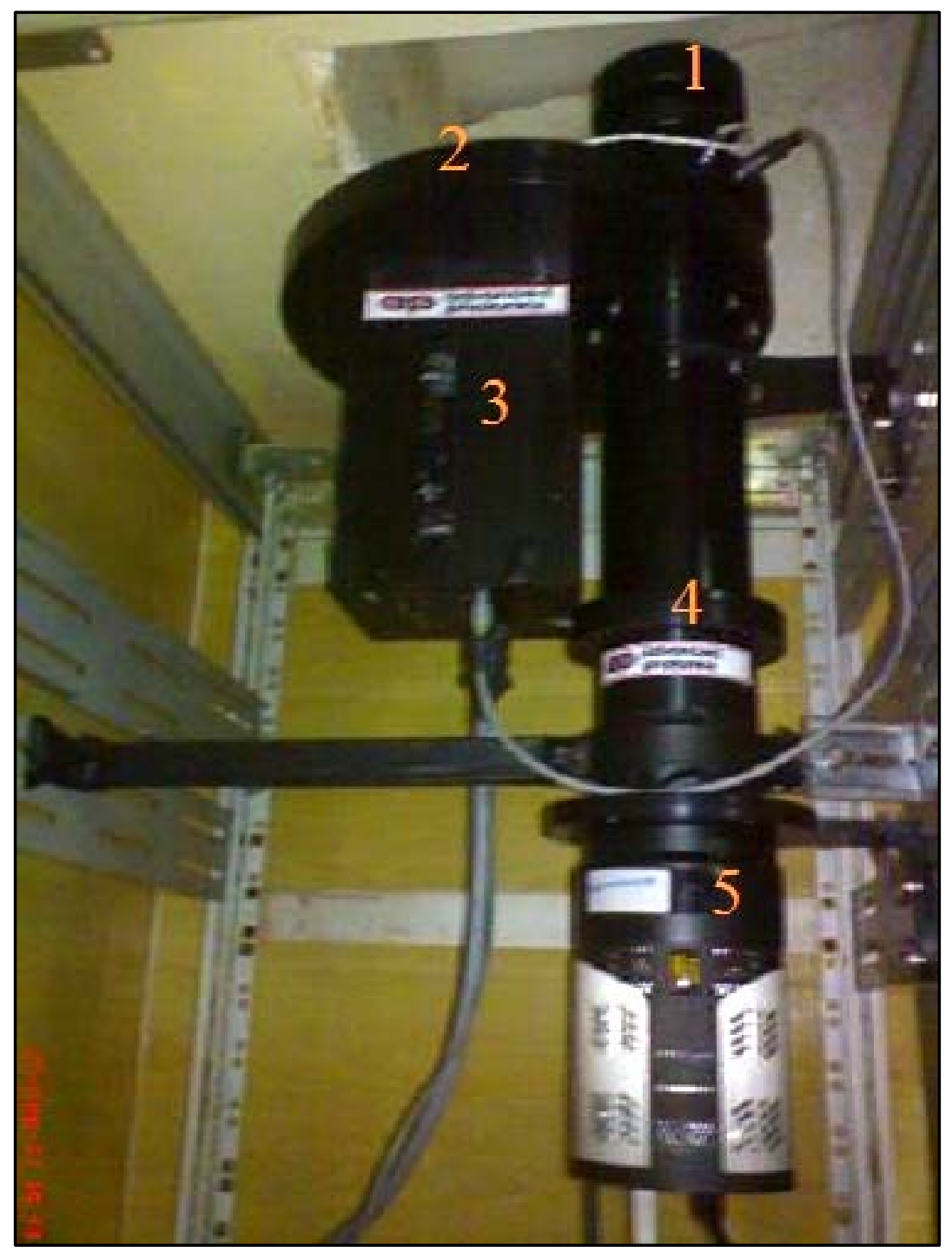

Fig. 1: A photograph of NARL all sky imaging system, where, 1 is fisheye lens, 2 is the filter wheel, 3 is the control of filter wheel, 4 is the camera lens and 5 is the CCD camera with Pixi-2024B CCD. 


\section{Method of Analysis}

Traditional analysis method follows the method described by Garcia et al. (1997). In this method, the exact field of view is determined using the star coordinates and then the angular picture taken by the imager is converted to the spatial scales which has been elaborated in recent investigations as well (e.g., Taori et al., 2013; Sharma et al., 2014). In addition to this, we need to a) remove the lens curvature effects and normalization of intensities and b) register the image sequence in the proposed method which demonstrates the spatio-temporal structures simultaneously.

\section{Removing the lens curvature effects}

While analyzing the images, often the flat fielding of images to correct for the intensity values are performed, but lens curvature effects remain mostly unaddressed. Removing the curvature from each image is important so that correct information about spatial structures noted in the image data can be obtained. For a simple solution of this issue, we designed an experiment as follows.

We prepare a calibration grid scale on a chart paper of $0.5 \mathrm{~mm}$ thickness with separation between each grids $20 \mathrm{~mm}$. This chart paper was glued to a flat aluminium sheet. The distance from the top of the imager (center of the fish eye lens) was made adjustable and we performed the experiment with distances of $62 \mathrm{~mm}$ and $124 \mathrm{~mm}$. Fig. 2 shows an image taken by the NAI at $630 \mathrm{~nm}$ filter at a distance of $62 \mathrm{~mm}$. Similar image was noted in other filters as well, however, as they provide no different information, we show only one image for the elaboration. It is evident from the Figure that at the edges the scales are not linear, i.e., they are distorted. Such distortion is termed as the Barrel distortion (e.g., Ma et al., 2003).

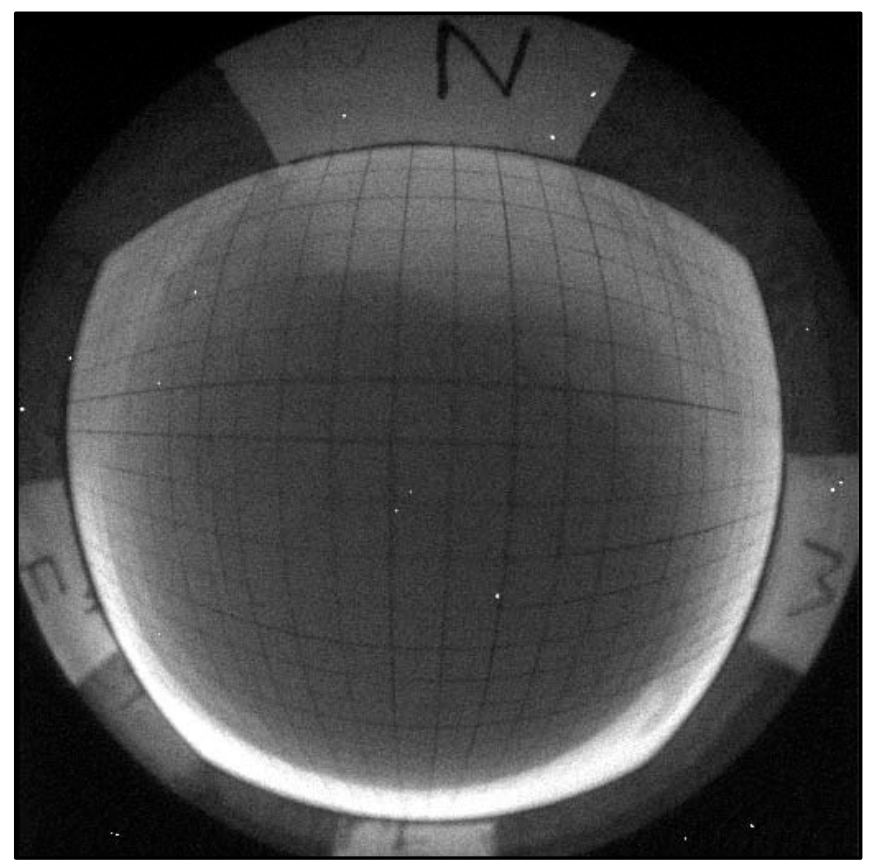

Fig.2: An all-sky image without calibration. The experimental grids with $20 \mathrm{~mm}$ separation are noteworthy in the image. 
Open access e-Journal

Earth Science India, eISSN: $0974-8350$

Vol. 8 (III), July, 2015, pp. 50 - 60

http://www.earthscienceindia.info/

To project a hemispherical image (raw image) onto a rectilinear plane, it is important to understand the process through which a fisheye image is recorded. The key difference between fisheye lenses and rectilinear lenses is that fisheye lens records angular view per unit recorded area where the rectilinear lense records unit distance per unit recorded area. Hence, in a fisheye lens ' $r=f \cdot \sin (\theta)$ ', where $r$ is the distance of the object image from the center of the image and ' $\theta$ ' is the angle that an object forms with the optical axis. To overcome these distortions, a transformation is required to project the hemispherical view onto a uniformly spaced geographical grid. This step would involve a movement of pixels, known as unwrapping. This can be done by first applying a parametric radial distortion model (e.g., Ma et al., 2003). By doing this, we can estimate the distortion coefficients, and correct the images. The radial distortion is governed by the following polynomial equation:

$r_{d}=r_{u}+k_{1} r_{u}^{3}+k_{2} r_{u}^{5}+\ldots \ldots$

Where, $r=\sqrt{\left.x^{2}+y^{2}\right)}, \quad r_{d}$ is the distorted radius and $r_{u}$ is the undistorted radius while the $\mathrm{k}_{1}, \mathrm{k}_{2} \ldots$ are the distortion coefficients. In a polynomial distortion model, distortion is mostly dominated by the first term. The relationship between distorted and undistorted image points thus becomes,

$x_{d}-x_{0}=\left(x_{u}-x_{0}\right)\left(1+k_{1} r_{u}^{2}\right)$

Where $x_{0}$ is initial guess value of the position and $k$ values are decided by the iterative process. In the present experiment, we know the $x_{0}$ value (through the separation between two lines, i.e., $20 \mathrm{~mm}$ ), hence finding out the value of distortion coefficient is straightforward (i.e., it is no more iterative and becomes simple best-fitting solution). Important to note is that in doing this transformation, each pixel need not have corresponding values, hence we have used $6^{\text {th }}$ degree Taylor's series to fit the values in order to obtain continuous values for the unknown pixels in two dimensions. We have performed this exercise on the cropped image for $100^{\circ}$ full field of view of image shown in Fig. 2. We find that the distortion coefficient for the NAI is 0.4. Using this we reconstructed the image and results are shown in Fig. 3. We can see that the edges are unwrapped into somewhat larger spatial scales and the full image is converted into a near linear scales.

\section{Registering the image sequence}

The evolution of the dimension of the structure and direction of its movement is the most valuable parameters which are derived from the images. To compress this information from numerous images (in our case 120 images on a given night) in couple of images, we select a small portion of the image with its center over the Gadanki (i.e., zenith) aligned to East-West direction and North-South direction. The small portion (slice of an image) selection is of rectangular shape having its length equal to the full cropped image size (i.e., 220 pixels) and thickness 3 pixels for the $630 \mathrm{~nm}$ image and 1 pixel in case of the $558 \mathrm{~nm}$ image. When the length is taken in the East-West (North-South) direction, then the image is known to have been registered for spatio-temporal variations in the East-West (North-South) direction. Once this registering is performed, the coordinates are frozen for the full set of images obtained on that night. Each slice of the image is assigned the time of that particular image. Now this registering process is applied to all the images and thus we obtain a matrix 
Revisiting the Airglow Image Analysis to Obtain and Visual Representation of the Spatial and Temporal Information: Sivakandan and Taori

having its 3-dimensions, time, East-West (North-South) pixels (distances) and the distribution of dark count values (or intensity). This means that we have the distribution of intensity data in East-West (North-South) as well as in the time domain.

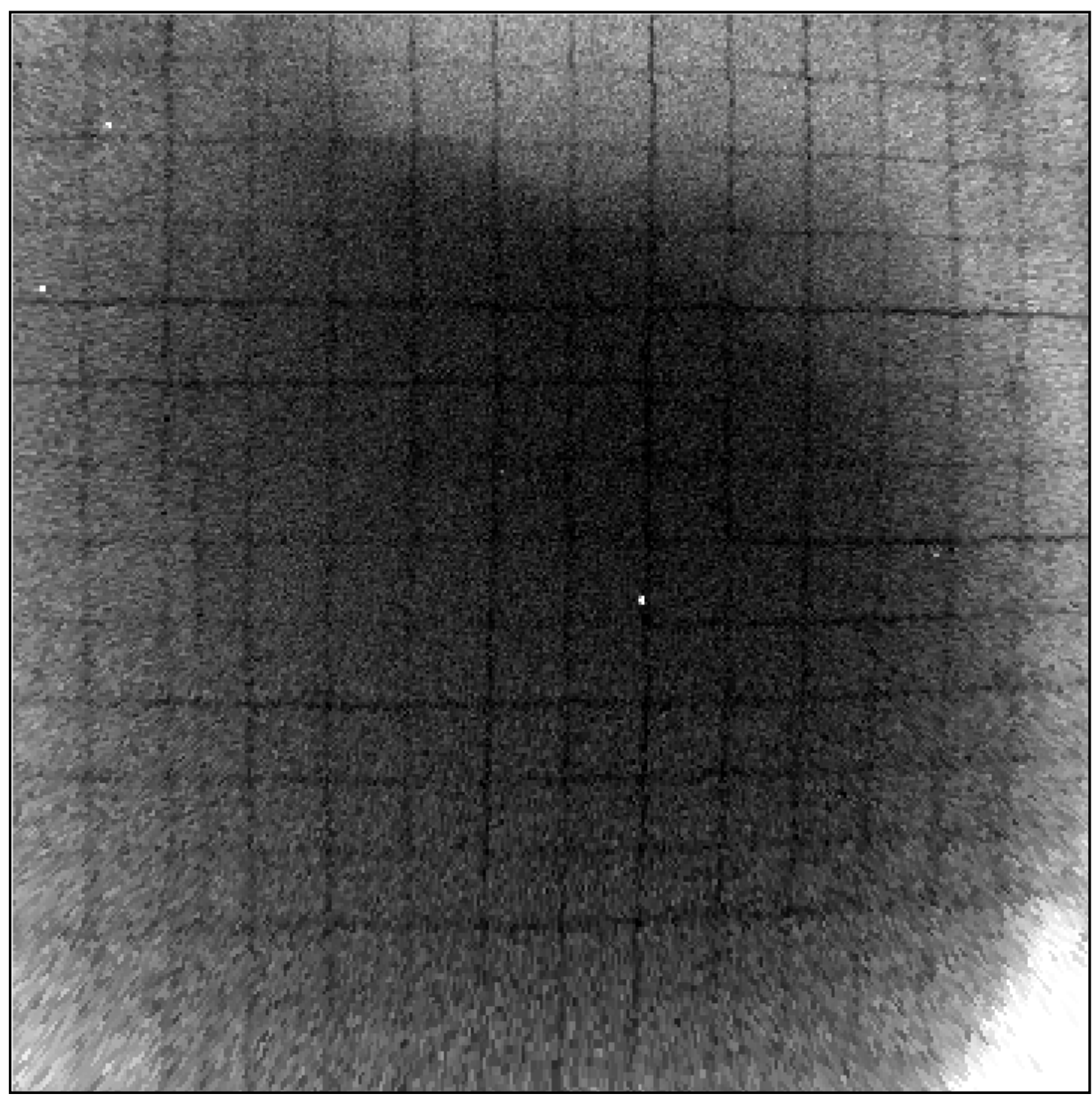

Fig.3: All-Sky image with distortion corrections for $100^{\circ}$ field of view.

We elaborate the above in Fig. 4 \& 5. Fig. 4 shows an example of analyzed images of $630.0 \mathrm{~nm}$ night airglow emissions corresponding to the observations made on $10^{\text {th }}$ April 2013. Note that analyzed images means that they have been a) cropped, b) adjusted for the contrast, c) flat fielded and d) as elaborated above, corrected for the lens curvature effects. The time corresponding to these measurements is shown at the topside of each image in yellow fonts. Note that there exist regions of depleted intensities. When noted carefully, we can see that this region has a structural shape which is north-south aligned. As it is occurring in the $\mathrm{F}$ - region of ionosphere with the emission process having electron densities involved, such structures represent the occurrence of equatorial plasma bubbles (EPBs) (e.g., Mukherjee et al., 2003; Makela and Otsuka, 2012). The differences in the EPB structures as time progresses indicate the evolution of the EPBs and that the dynamical conditions at 
Open access e-Journal

Earth Science India, eISSN: $0974-8350$

Vol. 8 (III), July, 2015, pp. 50 - 60

http://www.earthscienceindia.info/

ionospheric altitudes are varying from 16:33 UT to 19:57 UT. Note that when taking a slice of image around the zenith, then the east-west slice would record the movement occurring in the east - west direction with information on this structure at zenith (i.e., at zenith latitude, structures in longitude sector would be mapped). Similarly, the north-south alignment of the structure would be recorded in the slice taken in north to south direction (i.e., at zenith longitude, structures in latitudes would be mapped). The results of this image registration are shown in Fig. 5. The filled yellow stars mark the structures shown in Fig. 4. It is noteworthy that the structures noted in Fig. 4 are very clear in the Fig. 5 and also that the strength of depletions are also well captured. This kind of contour plot containing the registered images which represents the temporal as well as spatial variability is termed as 'keogram'. It is worth mentioning that the data before $1600 \mathrm{UT}$ is contaminated by the background lights hence is not reliable.

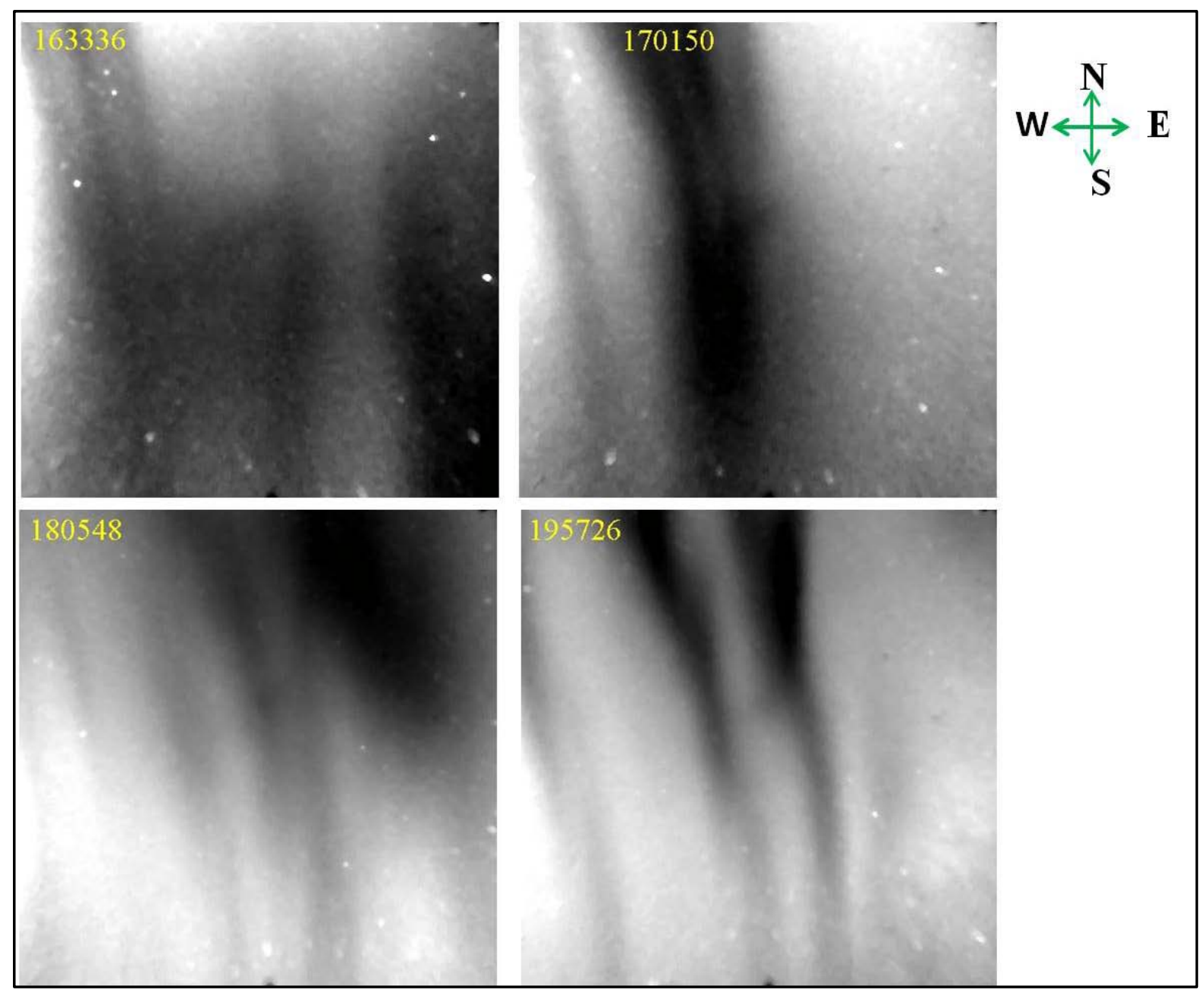

Fig.4: A sequence of $630 \mathrm{~nm}$ night airglow images on $10^{\text {th }}$ April, 2013 emphasizing the occurrence, evolution and propagation of EPBs. 
Revisiting the Airglow Image Analysis to Obtain and Visual Representation of the Spatial and Temporal Information: Sivakandan and Taori

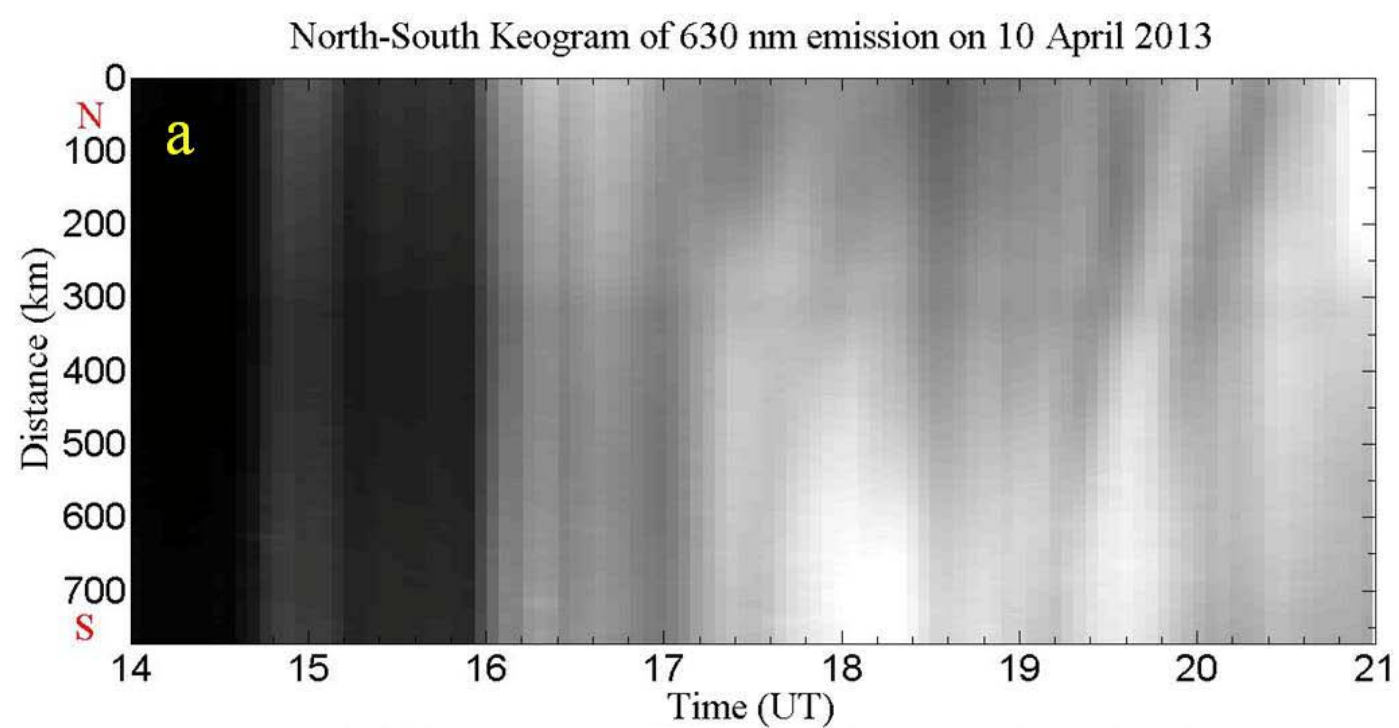

East-West Keogram of $630 \mathrm{~nm}$ emission on 10 April 2013

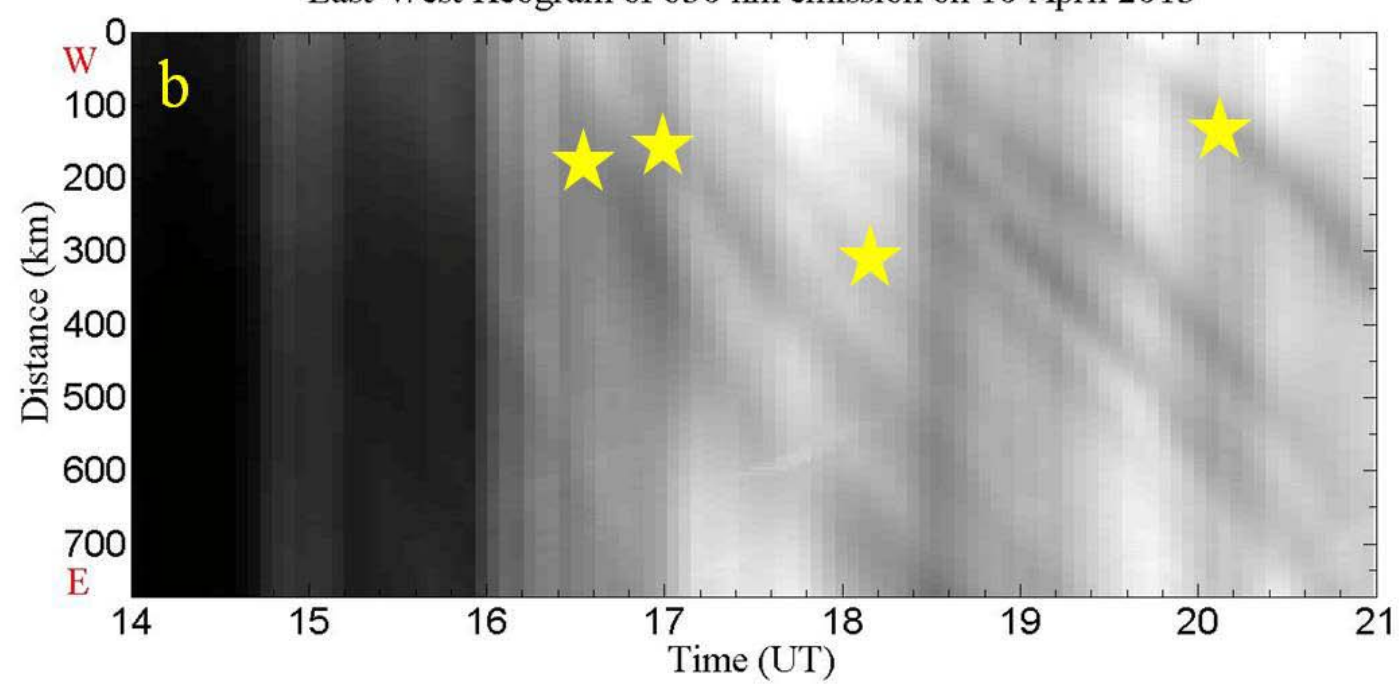

Fig.5: A sequence of $630 \mathrm{~nm}$ night airglow images emphasizing the occurrence, evolution and propagation of EPBs. The filled yellow stars show the position of the structures noted in Fig. 4.

\section{Derivable Results and Validation}

It is evident from Fig. 5 that we can get a) the distance between the structures in eastwest as well as in north-south direction and b) the slope of a particular structure in time domain. The former provides the scales of the structure (i.e., wavelength) while the latter is the velocity of that structure. In case of F-region $630 \mathrm{~nm}$ airglow emission, we the northsouth scale provides the information about the extent of EPB while the east-west scale would represent the inter depletion distances. Similarly, the north-south velocity would represent the evolution of the structures while the east-west velocity provide the drift motion of EPBs. It is noteworthy from Fig. 5a that depletion structures show variation in their north-south alignment, which represents that either plasma bubble may have gone to higher altitudes and because of field aligned nature, they are reflected in the data as tilted ones, or, there exists a shear flow at higher altitudes and as the bubble moved higher altitudes it resulted in tilted 
Open access e-Journal

Earth Science India, eISSN: $0974-8350$

Vol. 8 (III), July, 2015, pp. 50 - 60

http://www.earthscienceindia.info/

structure. Also, it is notable that the two EPB features occurred near simultaneously with about 30 min separation and these two features occurred in regular interval of about $1 \mathrm{hr}$. In Fig. 5b, it is noteworthy that structures show depleted region to come down as time progressed. This suggests that depletions were moving towards the East. The displacement can be noted from the $\mathrm{y}$-axis and time taken for this displacement from the x-axis. This, inturn provides an estimate of drift velocity. It is important to note that there are variations in the slope within a night, suggesting that the drift velocity vary with time.

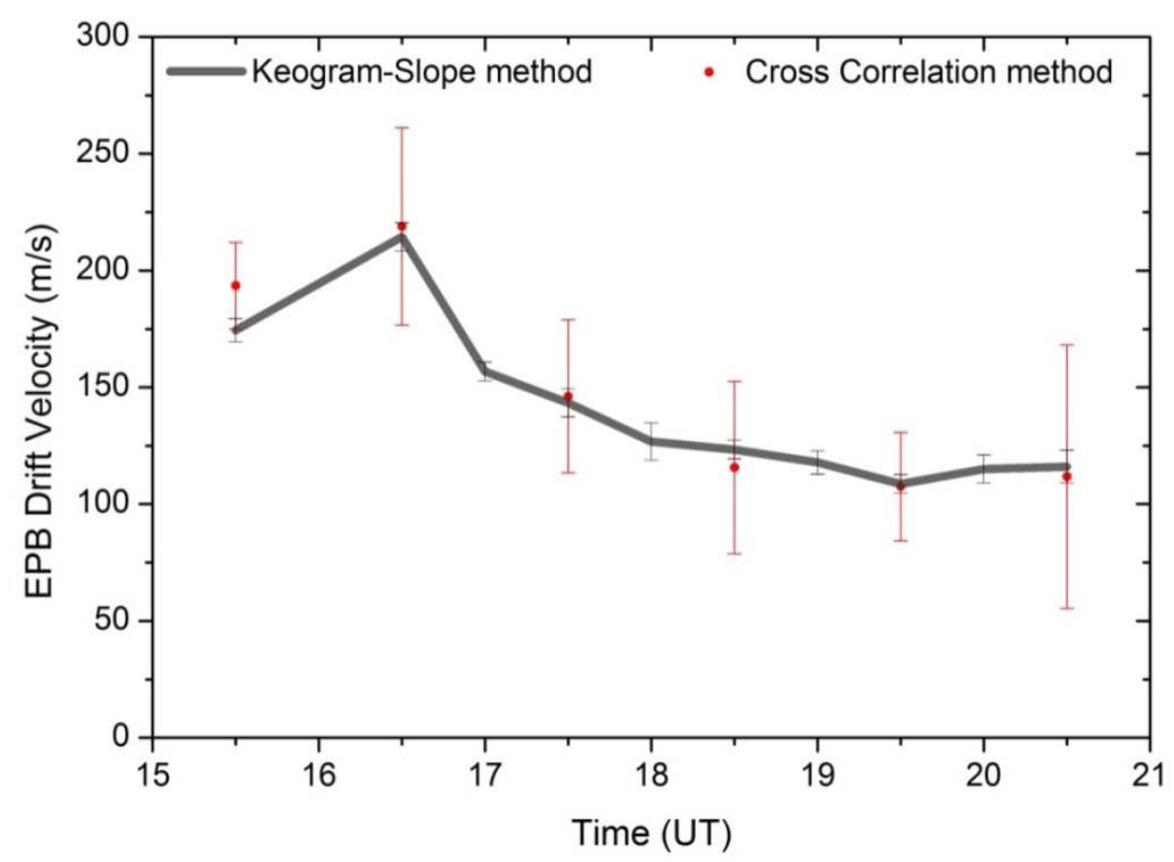

Fig.6: Comparison of drift velocity estimates using the traditional cross correlation method and slope method using keogram analysis.

To validate the method explained above, we compare our estimates with traditional method which use cross correlation analysis of one image to another. For a comparison of EPB drift velocity estimated using keogram with earlier explained methods (e.g., Taori et al., 2013; Sharma et al., 2014), we averaged the drift estimates for $30 \mathrm{~min} .$. In case, there were more than one EPB structure within 30 min., we averaged the estimates. Fig. 6 compares the estimation of drift velocity using these two methods. The gray connecting lines represent the slope method using the keograms shown in Fig. 5 while the filled red circles show the drift velocity estimates by cross correlation method from one image to another.

It is noteworthy that both methods suggest that drift velocity were maximum $(\sim 215$ $\mathrm{m} / \mathrm{s}$ ) at $\sim 1630$ UT and later slowly decrease to $\sim 100 \mathrm{~m} / \mathrm{s}$ by 2000 UT. This is in agreement with earlier reports from similar latitudes (e.g., Taori and Sindhya, 2014). It is notable that there is a very good agreement in the drift velocity estimates obtained by these two methods. It is also Important to note that the slope method which uses the keogram, has less variability, which results in less errors in the drift velocity estimates than the cross correlation method. It is worth mentioning that by such method one can show a compressed but approximately full information on the nocturnal variability noted. 


\section{Conclusions}

We have shown that the airglow image data which is more than 100 images on a given night can be represented in simple two contour maps named as 'keograms'. The derivable values which are obtained with the help of image-by-image analysis, can also be obtained with the help of keograms. Such kind of representation of atmospheric airglow data is important for understanding the existing anomalies in long data base which spans over several years. We believe that this is vital for the community as the short lived phenomena can be noted immediately by such analysis.

Acknowledgments: The present work is supported by the Department of Space, Government of India. The help of Mr. V. Kamalakar, Mr. Liyakat Basha and G. Ravikumar (M. Tech. Student) in carrying out experiments is duly acknowledged.

\section{References}

Batista, P.P., Takahashi, H., Gobbi, D., de Medeiros, A.F. (2000) First airglow all sky images at $23^{\circ}$ S. Advances in Space Research, v. 26, pp. 925-928.

Batista, P.P., Clemesha, B.R., Simonich, D.M., Taylor, M.J., Takahashi, H., Gobbi, D., Batista, I.S., Buriti, R.A. and de Medeiros, A.F. (2002) Simultaneous lidar observation of a sporadic sodium layer, a "wall"' event in the $\mathrm{OH}$ and OI5577 airglow images and the meteor winds. Journal of Atmospheric and Solar Terrestrial Physics, v. 64, pp.1327-1335.

Chakrabarty, D., Pant, T. K., Sekar, R., Taori, A., Modi, N. K. and Narayanan, R. (2002) Thermospheric temperature and magnetic field measurements from Mt Abu during a geomagnetically disturbed period - A case study. Current Science, v. 83, pp.167-170.

Chapagain, N. P., Makela J. J., Meriwether J. W., Fisher D. J., Buriti R. A., Medeiros A. F. (2012) Comparison of nighttime zonal neutral winds and equatorial plasma bubble drift velocities over Brazil. Journal of Geophysical Research, v. 117, doi: 10.1029/2012JA017620.

Ejiri, M. K., Nakamura, T. and Kawahara, T. D. (2010) Seasonal variation of nocturnal temperature and sodium density in the mesopause region observed by a resonance scatter lidar over Uji, Japan. Journal of Geophysical Research, v. 115, doi:10.1029/2009JD013799.

Ghodpage, R.N., Taori, A., Patil, P.T., Gurubaran, S., Sripathi, S., Banola, S. and Sharma, A.K. (2014) Simultaneous optical measurements of equatorial plasma bubble (EPB) from Kolhapur $\left(16.81^{\circ} \mathrm{N}\right.$, $\left.74.21^{\circ} \mathrm{E}\right)$ and Gadanki $\left(13.51^{\circ} \mathrm{N}, 79.21^{\circ} \mathrm{E}\right)$. Journal of Atmospheric and Solar Terrestrial Physics, v. 121, pp. 196-205, doi:10.1016/j.jastp.2014.05.008i.

Khomich, V. Y., Semenov, A. I. and Shefov, N. N. (2008) Airglow as an indicator of upper atmospheric structure and dynamics, Springer, Berlin.

Makela, J.J., Ledvina, B.M., Kelley, M.C. and Kintner, P.M. (2004) Analysis of the seasonal variations of equatorial plasma bubble occurrence observed from Haleakala, Hawaii. Annales Geophysicae, v. 22, pp. 3109-3121.

Ma Lili, Chen, Y., and Moore, Kevin L. (2004) Rational radial distortion models of camera lenses with analytical solution for distortion correction. International Journal of Information Acquisition, v.01 (135), doi: 10.1142/S0219878904000173.

Makela J. J. and Otsuka, Y. (2012) Overview of nighttime ionospheric instabilities at low- and mid-Latitudes: coupling aspects resulting in structuring at the mesoscale. Space Science Reviewes, v. 168, pp 419-440.

Mendillo, M., Baumgardner, J., Nottingham, D., Aarons, J., Reinisch, B., Scali, J. and Kelley, M.C. (1997) Investigations of thermospherc ionospheric dynamics with $6300 \AA$ images from the Arecibo Observatory. Journal of Geophysical Research, v.102, pp. 7331-7343.

Mukherjee, G. K. (2003) Studies of equatorial F-region depletions and dynamics using multiple wavelength nightglow imaging. Journal of Atmospheric and Solar Terrestrial Physics, v. 65, pp. 379-390.

Nakamura, T., A. Higashikawa, T. Tsuda, and Y. Matsushita (1999) Observations of gravity wave structures in OH airglow with a CCD imager at Shigaraki. Earth Planets Space, v. 51, pp. 897-906.

Narayanan, V. Lakshmi, Taori, A., Patra, A.K., Emperumal, K. and Gurubaran, S. (2012) On the importance of wave-like structures in the occurrence of equatorial plasma bubbles: A case study. Journal of Geophysical Research, v. 117, doi:10.1029/2011JA017054. 
Open access e-Journal

Earth Science India, eISSN: $0974-8350$

Vol. 8 (III), July, 2015, pp. 50 - 60

http://www.earthscienceindia.info/

Pimenta, A.A., Fagundes, P.R., Sahai, Y., Bittencourt, J.A. and Abalde, J.R.(2003) Equatorial F-region plasma depletion drifts: latitudinal and seasonal variations. Annales Geophysicae, v. 21, pp. 2315-2322.

Sharma, A.K., Nade, D.P., Nikte, S.S., Ghodpage, R.N., Patil, P.T., Rokade, M.V., Vhatkar, R.S. and Gurubaran, S. (2014) Development of fast image analysis technique for all sky images. Current Science, v.106, pp.1085-1093.

Sivakandan, M., A. Taori, S. Sathishkumar, and A. Jayaraman (2015) Multi-instrument investigation of a mesospheric gravity wave event absorbed into background. Journal of Geophysical Research, v. 120, doi:10.1002/2014JA020896.

Sridharan, R., Modi, N.K., Pallam Raju, D., Narayanan, R., Pant, T., Taori, A. and Chakrabarty, D. (1998) Multiwavelength daytime photometer-a new tool for the investigations of the atmospheric processes. Measurement Science \& Technology, v. 9, pp. 585-591.

Sridharan, R., A. Taori, S. Gurubaran, R. Rajaram, and Shepherd, M. G. (1998) First results on daytime mesopause temperatures using ground based photometry from equatorial latitudes. Journal of Atmospheric and Solar Terrestrial Physics, v. 61, pp. 1131-1142.

Takahashi, H., Batista, P.P., Sahai, Y. and Clemesha, B. R. (1985) Atmospheric wave propagations in the mesopause region observed by the $\mathrm{OH}(8,3)$ band, $\mathrm{NaD}, \mathrm{O}_{2} \mathrm{~A}(8645 \mathrm{~A})$ band and $0 \mathrm{I} 5577 \mathrm{~A}$ nightglow emissions. Planetary and Space Sciences, v. 33, pp. 381-384.

Taori, A., Sridharan, R., Chakrabarty, D., Narayanan, R., Ramarao, P.V.S. (2001) Coordinated thermospheric day-night airglow and ionospheric measurements from low latitudes-first results. Geophysical Research Letters, v. 28, pp. 1387-1390.

Taori, A., Sridharan, R., Chakrabarty, D., Modi, N. K. and R. Narayanan (2003) Significant thermospheric contribution in the $557.7 \mathrm{~nm} \mathrm{O}\left({ }^{1} \mathrm{~S}\right)$ dayglow: ground based evidences. Journal of Atmospheric and Solar Terrestrial Physics, v. 65, pp. $121-128$.

Taori, A., Taylor, M. J. and Franke, S. (2005) Terdiurnal wave signatures in the upper mesospheric temperature and their association with the wind fields at low latitudes $\left(20^{\circ} \mathrm{N}\right)$. Journal of Geophysical Research, v. 110, doi:10.1029/2004JD004564.

Taori, A., Makela, J. J. and Taylor, M. (2010) Mesospheric wave signatures and equatorial plasma bubbles: A case study. Journal of Geophysical Research, v.115, A06302, doi:10.1029/2009JA015088.

Taori, A., Dashora, N., Raghunath, K., Rusell III, J. M. and Mlynczak, M. G. (2011) Simultaneous mesosphere, thermosphere-ionosphere parameter measurements over Gadanki $\left(13.5^{\circ} \mathrm{N}, 79.2^{\circ} \mathrm{E}\right)$ - First results. Journal of Geophysical Research, v. 116, doi:10.1029/2010JA016154.

Taori, A., Kamalakar, V., Raghunath, K., Rao, S. V. B. and Russell III, J. M. (2012) Simultaneous Rayleigh lidar and airglow measurements of middle atmospheric waves over low latitudes in India. Journal of Atmospheric and Solar Terrestrial Physics, v.78, doi:10.1016/j.jastp.2011.06.012.

Taori, A., Jayaraman, A., Raghunath, K. and Kamalakar, V. (2012) A new method to derive middle atmospheric temperature profiles using a combination of Rayleigh lidar and $\mathrm{O}_{2}$ airglow temperatures measurements. Annales Geophysicae, v. 30, pp. 27-32, doi:10.5194/angeo-2012.

Taori, A., Jayaraman, A. and Kamalakar, V. (2013) Imaging of mesosphere - thermosphere airglow emissions over Gadanki $\left(13.5^{\circ} \mathrm{N}, 79.2^{\circ} \mathrm{E}\right)$ - first results. Journal of Atmospheric and Solar Terrestrial Physics, v. 93, pp.21-28, doi:10.1016/j.jastp.2012.11.007.

Taori, A. and Sindhya, A. (2014) Measurements of equatorial plasma depletion velocity using $630 \mathrm{~nm}$ airglow imaging over a low-latitude Indian station. Journal of Geophysical Research, v. 118, doi: 10.1002/2013JA019465.

Taylor, M., Pendleton Jr., W.R., Clark, S., Takahashi, H., Gobbi, D., Goldberg, R. A. (1997) Image measurements of short-period gravity waves at equatorial latitudes. Journal of Geophysical Research, v. 102, pp. 26283-26299.

Taylor, M. (1998) A review of advances in imaging techniques for measuring short period gravity waves in the mesosphere and lower thermosphere, Advances in Space Research, v. 19, pp. 667-676.

Taylor, M., Taori, A., Hatch, D. R., Liu, H. L. and Roble, R. G. (2005) Characterization of the Semi-AnnualOscillation in Mesospheric Temperatures at Low-Latitudes. Advances in Space Research, v. 35, pp. $2037-2043$. 